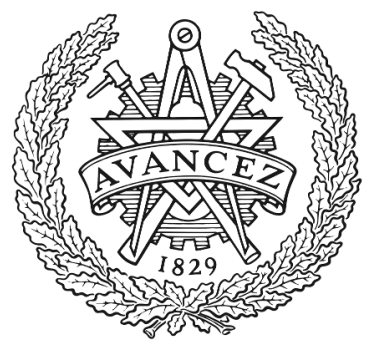

CHALMERS

UNIVERSITY OF TECHNOLOGY

\title{
Control strategies for refiners Part I: Soft sensors for CD-refiner control
}

Downloaded from: https://research.chalmers.se, 2023-04-26 05:22 UTC

Citation for the original published paper (version of record):

Karlström, A., Hill, J. (2018). Control strategies for refiners Part I: Soft sensors for CD-refiner control. Nordic Pulp and Paper Research Journal, 33(1): 28-43. http://dx.doi.org/10.1515/npprj-2018-3007

N.B. When citing this work, cite the original published paper. 


\section{Mechanical pulping}

Anders Karlström* and Jan Hill

\section{Control strategies for refiners Part I: Soft sensors for CD-refiner control}

https://doi.org/10.1515/npprj-2018-3007

Received August 9, 2017; accepted December 11, 2017; previously published online February 24, 2018 on www.npprj.se

Abstract: Internal variables in (C)TMP-refining processes (e. g. temperature, consistency, fiber residence time, backward flowing steam and forces acting upon the chips and pulp) are defined as physical states obtained in different parts of the refining zones. In short, they differ from the traditional external variables (e. g. dilution water feed rate and specific energy) which are not obtained from measurements or physical models of the process in the refining zone. The internal variables are the backbone of physical models and are used in this paper as soft sensors for advanced process control. Besides the shape of the temperature profile, the position of the maximum temperature and the shape of the consistency profiles inside the refining zones are important to control as they are directly linked to the development of different pulp and handsheet properties. To illustrate the capability when using combined modeling and control strategies, the concept is applied on a full scale CD82 refiner. This means both temperature and consistency control in the flat zone and the conical zone, together with an overall estimator for fiber development. Finally, in this paper it is shown that the production can be increased significantly without changing the refiner motor load nor violating the pulp property specification.

Keywords: consistency; control; CTMP; energy efficiency; motor load distribution; pulp; temperature profile.

\section{Introduction}

Previous studies of the control performance in general have shown that reasons for poor control often include problems with the tuning of basic single-input-singleoutput (SISO) controllers as well as equipment problems (sticking valves etc.), see Horch (1999) and Hägglund (1999). Traditional methods that aim to improve the per-

*Corresponding author: Anders Karlström, Chalmers University of Technology, Göteborg, Sweden, e-mail: anderska@chalmers.se Jan Hill, QualTech AB, Tyringe, Sweden, e-mail: jan.hill@qtab.se formance, by logging inspections of control loop hardware and the percentage of the time when the loops are in automatic mode, are now standard procedure. However, in many cases, a lack of process information is a serious problem in terms of taking different control concepts a step further, especially when building more advanced control concepts based on a multi-input-multi-output (MIMO) structure.

Most papers dealing with refiner optimization and control confine themselves to discussing the topic either with the perspective of an individual refiner or an individual (C)TMP production line, see Hill et al. (1979), Johansson et al. (1980), Dahlqvist and Ferrari (1981), Oksum (1983), Honkasalo et al. (1989), Hill et al. (1993), Berg (2005), Eriksson (2005) and Eriksson (2009). The literature is sparse in the combining of control and advanced physical modeling concepts, especially when it comes to the control of pulp and handsheet properties. During the late 1980s, Miles and May $(1990,1991)$ derived a theoretical model of the pulp flow behavior in the refining zone of a high consistency (HC) refiner. A theory became widely used and gave a better understanding of refining. However, Isaksson et al. (1997) and Sabourin et al. (2001) claimed that the model derived by Miles and May (1990, 1991) is not suitable for practical use in full-scale refiners since it has too many unknown parameters and variables. This statement was the starting point for deriving a completely new model based on first principals, see Karlström et al. (2005), Berg (2005), Karlström et al. (2008), Eriksson (2009) and Karlström (2013), who introduced spatial temperature measurements inside the refining zone to span the material and energy balances. This led to the possibility to analyze the distributed work as well. The model was thereafter completed by Karlström and Eriksson (2014a,b,c,d) and Karlström and Hill (2014a,b and 2015a,b) to cover inlet and outlet conditions which are important for control purposes.

One reason why the implementation of such physical models based on first principals on-line has taken such a long time is that the model complexity sometimes itself 
introduces barriers. Karlström and Eriksson (2014a,b,c,d) verified the models using a 3D model structure to cope with different time scales, geometries and important physical variables such as the spatially dependent pulp viscosity. Later, the structure was reduced to include only radial considerations where the distributed viscosity estimation added more value to the understanding than originally expected. This was not only the primary motivation; it was also important to secure the time-sampling aspects necessary to implement the model on-line, see Karlström and Hill (2017a,b,c).

This paper focuses on the control issues where the interplay between internal variables (e.g. temperature and consistency) and external variables (e. g. dilution water feed rate, specific energy (i.e. the ratio of the motor load to the production rate) and plate clearance) is vital.

The distinction between internal and external variables as indicated above was introduced by Karlström and Isaksson (2009) and further developed by Karlström et al. (2015, 2016a,b). It was shown that using internal variables instead of external variables to find proper piecewise linear models, estimating pulp and handsheet properties, gave a better opportunity to handle inherent nonlinearities in the process. These results were to some extent not expected, as the major efforts to derive pulp and handsheet properties had thus far been based on external variables as independent variables, see Strand (1996), Strand and Grace (2014) and Lehtonen et al. (2014). Lately, Karlström and Hill (2017a,b,c) have shown that non-linearities caused by the refining process itself can be handled if internal variables, measured or derived from a physical model, are available. The reason for this is that the pulp and handsheet properties seem to be more linearly dependent on the internal variables. This might be one reason why earlier efforts to control external variables such as specific energy and blow-line consistency sometimes caused problems because of the lack of refining zone information or non-linear aspects difficult to foresee using only external variables.

This paper presents one way to use soft sensors in online applications. The model comprises a complete refiner including systems descriptions for inlet mixing zones, refining zones and outlet mixing zones. The model copes with real-time process changes and is the backbone in the control concepts for CD refiners. The hypothesis presented here is that process information from such a model, in terms of temperature measurements and consistency estimations in FZ and CD, can be used when searching for different optimal operating conditions.

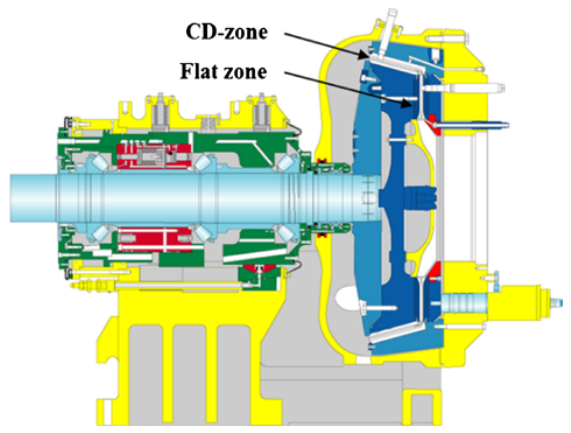

Figure 1: A schematic drawing of a CD refiner. The vertical flat zone (FZ) is directly linked to the conical zone (CD) via an expanding point.

\section{Materials and methods}

Data from a full-scale CTMP production line - see further Karlström and Hill (2017a,b,c) - are investigated. Figure 1 shows the CD82-refiner that has been used.

From a control engineering perspective, we can see that the CD82 refiner comprises two serially linked refining zones - see Figure 2. The pulp quality in the FZ and CDzones can be manipulated individually by changing the process input vector, $u=[S, D, P]$. The vector consists of the elements of plate gap or hydraulic pressure for closing the refining zone ${ }^{1}(S)$. The dilution water feed rate $(D)$ is added before the FZ- and at the middle of the CD-zones. The production, i. e. wood chip feed rate $(P)$, is fed into the center of the refiner by the feeding screw.

The production is of course the same in both refining zones while the plate gap and dilution water added are individual for each zone and therefore divided according to $\left[S_{F Z}, D_{F Z}\right]$ and $\left[S_{C D}, D_{C D}\right]$, respectively.

The traditional way to control a CD-refiner is to find an operating point with good enough pulp quality to a certain specific energy by primarily changing the process conditions in the CD-zone. The flat zone is to some extent more difficult to control as the motor load split between FZ and CD is not available. ${ }^{2}$ This has been discussed for decades and to overcome such problems in this paper sensor arrays were used to measure the temperature at eight positions along the radius in both the flat zone (FZ) and the conical zone (CD) see Figure 3.

The measurements in each zone opens for a possibility to span the material and energy balances in the process,

1 In Figure 2, this corresponds to $\Delta_{F Z}(r)$ and $\Delta_{C D}(r)$. The reason why we change notation to $S$ is that the plate gap is measured in one specific position and not along the radius.

2 Only the total motor load is possible to monitor. 


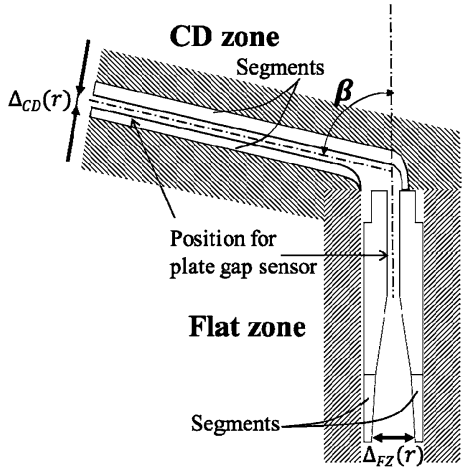

Figure 2: A schematic drawing of the refining zones in a CD refiner. The vertical flat zone (FZ) is directly linked to the conical zone (CD) via an expanding point.

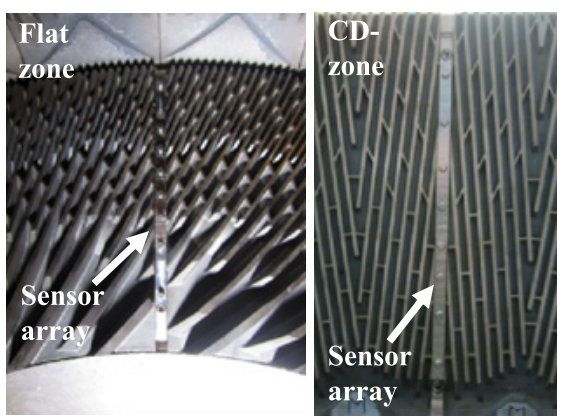

Figure 3: Sensor arrays mounted between refining segments in a CD82-refiner.

see Karlström and Eriksson (2014a,b,c,d) and Appendix for details. This was originally motivated by Karlström et al. (2008) as a consequence of the extremely fast dynamics in the refining zone (ranging from 0.5 to $1 \mathrm{~s}$ ) together with the slower actuator dynamics for plate gap changes and the overall dominant dynamics in the inlet and outlet piping. All this limits the possibilities to control the refiner fast enough to cope with the instant refining zone dynamics, see the further discussion in Karlström and Hill (2014a,b, 2015a) and Karlström et al. (2015b). The combination of fast and slow dynamics also opens the possibility for a robust on-line implementation of the physical model.

The most common situation in the pulp and paper industry today is that internal variables, such as the temperature profiles, are not available for control. This means that the system description using the specific energy, ${ }^{3} y_{E}$

3 The motor load is normally seen as an output while the production rate, i. e. the chip feed rate to the refiner line, is an input. Therefore, from a control engineering perspective, the specific energy control concept is questionable. and the estimated consistency in the blow-line, $y_{C}$, become

$$
\begin{aligned}
y & =\left[\begin{array}{l}
y_{E} \\
y_{C}
\end{array}\right] \\
& =G u=\left[\begin{array}{lllll}
g_{11} & g_{12} & g_{13} & g_{14} & g_{15} \\
g_{21} & g_{22} & g_{23} & g_{24} & g_{25}
\end{array}\right]\left[\begin{array}{c}
S_{F Z} \\
D_{F Z} \\
S_{C D} \\
D_{C D} \\
P
\end{array}\right]
\end{aligned}
$$

where $G$ is the transfer function matrix describing the process dynamics. This is a typical MIMO structure where the elements in $G$ are time varying and difficult to derive. As an example, it is well-known that specific energy is nonlinearly dependent on changes in the input vector $u$ which is cumbersome when introducing advanced control concepts.

Another drawback of the process description in Equation 1 is that the specific energy is impossible to split into the defibration/fibrillation work in FZ and CD without using more sophisticated models, as described in the Appendix. However, by using internal variables instead, an alternative control concept can be formulated.

As described by Karlström and Hill (2017a,b,c), the maximum temperatures in $\mathrm{FZ}$ and $\mathrm{CD}$ are almost unaffected by changes in the dilution water feed rates to the refining zones, which opens for a number of possibilities to describe the process in another way. Let the internal variable sets, $\left[T_{\operatorname{maxFZ}}, C_{\operatorname{maxFZ}}\right]$ and $\left[T_{\max C D}, C_{\max C D}\right]$, comprise the maximum temperatures and the consistencies. Note that these two vectors contain two scalars where the consistency scalars are obtained from the profile at the periphery for each refining zone. ${ }^{4}$

By introducing the pulp quality, $Q$, a simple form of the output vector, $y$, is obtained at the same time as the system complexity can be reduced considerably due to natural decoupling phenomena, see Equation 2 and Karlström and Hill (2015a).

$$
\begin{gathered}
y=\left[\begin{array}{c}
T_{\max F Z} \\
C_{\max } F Z \\
T_{\max } C D \\
C_{\max C D} \\
Q
\end{array}\right] \\
=G u=\left[\begin{array}{ccccc}
g_{11} & & & & g_{15} \\
& g_{22} & & & g_{25} \\
& & g_{33} & & g_{35} \\
& g_{42} & & g_{44} & g_{45} \\
g_{51} & g_{52} & g_{53} & g_{54} & g_{55}
\end{array}\right]\left[\begin{array}{c}
S_{F Z} \\
D_{F Z} \\
S_{C D} \\
D_{C D} P
\end{array}\right]
\end{gathered}
$$

4 In this paper, the outlet consistencies are used in the system description because the flat and conical zones are serially linked. 
Hence, in total, we have a sparse $5 \times 5$ system $^{5}$ to handle but normally, the aim is to keep the production as stable as possible which means that we can reduce the system complexity in Equation 2 even further. The reason is that any disturbance in production is captured by the temperature profile measurements and other internal variables such as consistencies, see Karlström and Hill (2014a,b, 2015a) and Karlström et al. (2015b).

$$
\begin{aligned}
y & =\left[\begin{array}{c}
T_{\max F Z} \\
C_{\max F Z} \\
T_{\max C D} \\
C_{\max C D}
\end{array}\right] \\
& =G u=\left[\begin{array}{llll}
g_{11} & & g_{13} & \\
& g_{22} & & \\
& & g_{33} & \\
& g_{42} & & g_{44}
\end{array}\right]\left[\begin{array}{c}
S_{F Z} \\
D_{F Z} \\
S_{C D} \\
D_{C D}
\end{array}\right]
\end{aligned}
$$

In Equation $3 g_{13} \neq 0$, while in Equation 2 it is zero. This is a consequence of new results obtained at specific operating conditions where the conical zone is significantly loaded.

Moreover, we can conclude that the element $g_{42} \neq 0$, i. e. the relationship between the dilution water in the flat zone and the consistency in the $\mathrm{CD}$ zone, must be handled in traditional linear simulations. However, as the consistencies can be estimated by the physical model discussed in the Appendix, it is possible to get both $C_{\operatorname{maxFZ}}$ and $C_{\max C D}$ instantly every sample. The concept can be illustrated by using SIMULINK ${ }^{6}$ for the proposed consistency controllers. As seen in Figure 4, each controller has a cascade structure where the soft sensor provides information about the necessary non-linear internal variables such as consistency profiles as well as the fiber residence times, backward and forward flowing steam etc. in the flat and the conical zones. ${ }^{7}$

The loops for controlling the maximum temperatures in each refining zone are traditional SISO loops and are not illustrated in this paper.

Karlström and Hill (2017a,b,c) recently showed that the internal variables are favorable and outperform the external variables as predictors when formulating linear esti-

5 Note that the matrix includes the pulp quality only to give the reader information about the fact that it is affected by all process inputs. Moreover, the pulp quality must be described by several pulp or handsheet properties but normally only a few of these are the prime candidates in control concepts, see Karlström and Hill (2017a,b,c).

6 Simulink ${ }^{\circledR}$ is a commercial block diagram environment for multidomain simulation and Model-Based Design, see further www.mathworks.com/help/simulink/

7 Hence, by using the soft sensor, we do not have to consider the element $g_{42}$ in Equation 3 as it is already handled by the soft sensor.

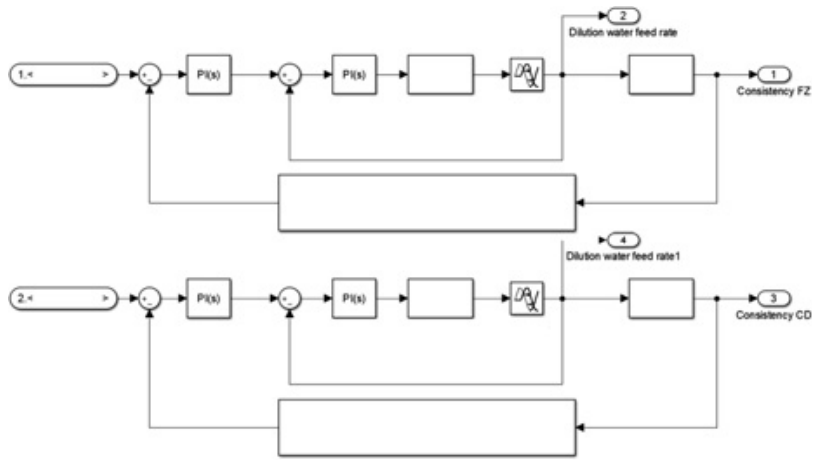

Figure 4: Consistency controllers for the flat and conical zones in a CD refiner. Simulation illustrates using SIMULINK notation.

mations of pulp and handsheet properties, see Equation 4.

$$
\hat{f}_{m}\left(\overline{\boldsymbol{x}}_{m}\right)=\theta_{0}+\theta_{1} \bar{x}_{1}+\theta_{2} \bar{x}_{2}+\cdots+\theta_{k} \bar{x}_{k}
$$

where $\left\{\theta_{1}, \ldots, \theta_{k}\right\}$ represents the parameter vector and $k$ the number of mean predictors, $\bar{x}$, (Lowe and Zohdy (2010)) obtained according to the sampling procedure outlined by Karlström and Hill (2017b,c).

The consistencies and fiber residence times turned out to be especially essential when estimating pulp and handsheet properties; see Figure 5 where the model inputs and outputs are illustrated.

This simplified approach has proven to be relatively robust and useful when studying variations in pulp and handsheet properties, see Table 1.

As seen in Table 1, the parameters for the consistency are highlighted to show that the handsheet properties in terms of tensile index, Scott bond and Z-strength respond in a similar direction. Karlström and Hill (2017c) also showed that the consistencies in the flat and conical zones are dominating predictors when estimating the pulp and handsheet properties.

Following the hypothesis outlined above, i. e. that process information from both $\mathrm{FZ}$ and $\mathrm{CD}$ can be used when optimizing the operating conditions a test was performed according to Figure 6. As seen, the traditional way to control the refiner by manipulating $S_{C D}$ and $D_{C D}$ has been modified by introducing an unorthodox strategy where the plate gaps and the dilution water feed rates, in both FZ and CD-zones, are controlled simultaneously. The aim with the test was to see if these changes can result in an increased production.

\section{Results and discussion}

In this paper we propose that the process is stabilized in three steps to 


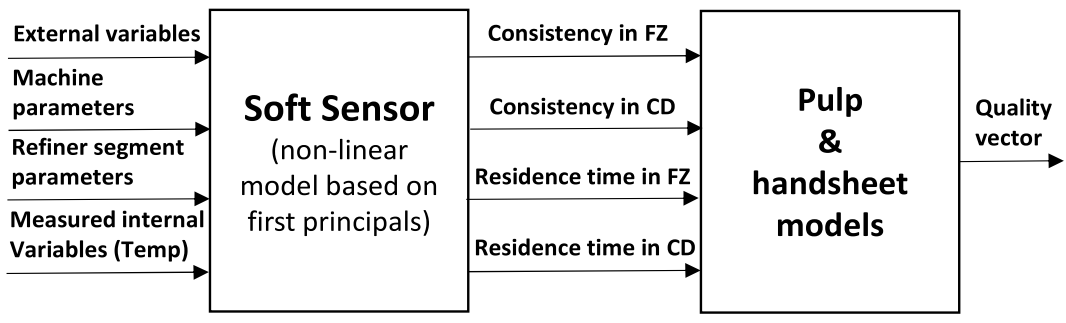

Figure 5: Schematic description of the soft sensor and the regression model for pulp and handsheet property estimation.

Table 1: Model parameters for pulp and handsheet properties based on results presented by Karlström and Hill (2017b).

\begin{tabular}{lrrrrr}
\hline Properties & Intercept & Cons.(FZ) & Cons.(CD) & R.time(FZ) & R.time(CD) \\
\hline CSF Freeness & 767.4522 & 6.5706 & -5.3285 & -320.0951 & 1430.6061 \\
Sheet density & 311.3555 & -13.5518 & 7.6204 & 100.8509 & 55.8056 \\
Tensile strength & -3.5278 & -0.1770 & 0.0831 & -3.6486 & 62.7926 \\
Tensile index & 40.2999 & $-\mathbf{2 . 1 9 2 5}$ & $\mathbf{1 . 0 2 4 5}$ & -16.5077 & 200.9831 \\
Elongation to rupture & 1.6649 & -0.0341 & 0.0143 & -0.7405 & 6.0259 \\
Tensile energy absorption & 80.0754 & -4.2263 & 2.2176 & -38.5411 & 314.1703 \\
Tensile energy absorption index & 0.4283 & -0.0111 & 0.0046 & 0.7856 & -4.6984 \\
Tensile stiffness & -451.7375 & -5.3301 & 1.3169 & 1757.0678 & -6261.3361 \\
Tensile stiffness index & 5.2630 & -0.0675 & -0.0026 & 0.5462 & -1.9310 \\
Tear strength & 6435.5391 & -14.0063 & 0.2833 & 811.0374 & -25020.3831 \\
Tear index & 53.1587 & -0.1836 & 0.0703 & -5.6864 & -140.9302 \\
Short-span compressive test index & 24.1904 & -0.6072 & 0.3068 & -1.8931 & 10.6965 \\
ISO brightness & 88.6031 & -0.7198 & 0.0572 & -57.3180 & 331.3528 \\
Scott-Bond & 155.0146 & -7.2287 & 3.5924 & 120.7834 & -508.4503 \\
Z-strength & 144.0442 & -6.0570 & 3.1333 & -129.1267 & 890.5317 \\
Shives(>=0.3mm) & -1787.1167 & -53.8174 & 94.7427 & -1459.5470 & 10070.7017 \\
Long fibers & 8.0583 & -0.0944 & -0.0102 & -8.7292 & 47.3025 \\
Fines & 34.3848 & 0.2466 & -0.6137 & 70.0445 & -240.6360 \\
\hline
\end{tabular}
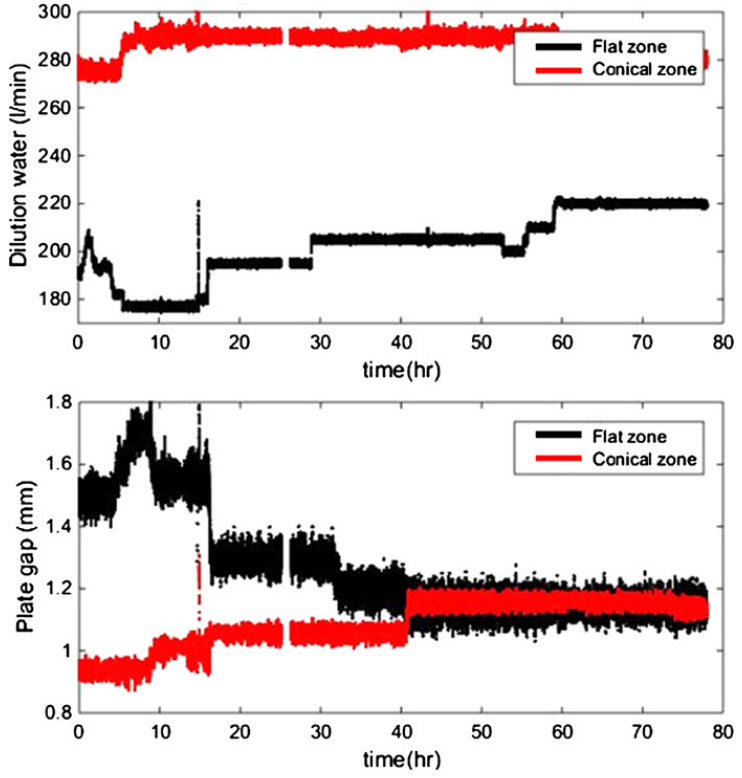

Figure 6: Step changes performed in the external variables of dilution water and plate gap.
1. reach desired operating conditions before;

2. optimizing production and finally;

3. introduce the complete set of control algorithms for tuning pulp and handsheet properties.

When all algorithms are in automatic mode, the primary aim is to maintain the process at the desired production level and tune the pulp and handsheet properties using the knowledge from Table 1.

Reach desired operating conditions: We have concluded that the maximum temperatures in each zone correspond to the steam turning point where $\partial P / \partial r \approx 0$ and, to minimize the fluctuations in the forward flowing steam, we claim the following

$$
T_{\max F Z}>T_{\max C D}
$$

This stabilizes the fiber pad inside the refining zones as the entire temperature profile is stabilized along the radius. In other words, a varying position of the maximum temperature will affect the steam, which of course also will 


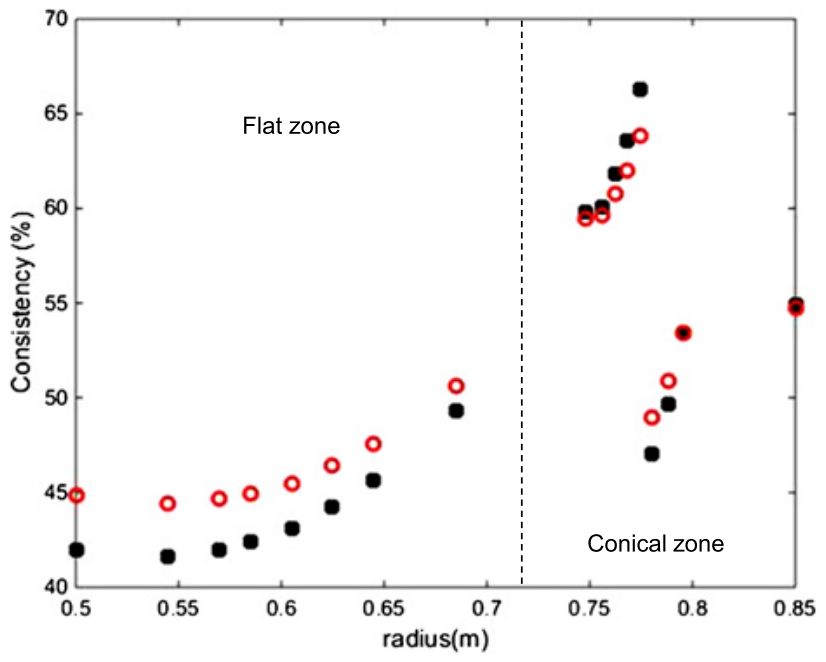

Figure 7: Two consistency profiles where the outlet consistency in the blow-line is controlled while the consistency profile in the flat zone varies. The profiles are averaged based on 1000 samples (seconds) during relatively stable conditions. Note that the drastic change in the conical zone is a consequence of the position at which the dilution water is added.

affect the fiber-to-bar interaction, see Karlström and Eriksson (2014a,b,c,d). These fluctuations consequently provide variations in the pulp and handsheet properties and a relatively large specific energy variance, see Karlström and Hill (2017a). ${ }^{8}$ To handle operating conditions where $g_{13} \neq 0$ it is also wise to maintain the relationship between $T_{\operatorname{maxFZ}}$ and $T_{\max C D}$.

The consistency profile turns out to be invaluable when trying to optimize the refining process, develop new refining segment patterns etc.

When manipulating the plate gaps, the consistency in the outlet of the flat and the conical zones must be followed closely to reach the desired temperature profile.

To help the operators to handle the situation it is wise to initially set

$$
C_{\max F Z} \approx C_{\max C D}
$$

This is a normal start-up situation in serially linked refiners and thereby also applicable in CD-refiners.

It is important to note that these maxima always correspond to the periphery positions in the refining zones, i. e. they do not coincide with the positions obtained for the temperature maxima, see Figure 7 and Figure 21 in Ap-

8 Note that the type of the refining segment pattern and the refining segments' condition due to plate wear can affect the magnitude of the temperature difference in the flat zone and conical zone, but in normal situations the difference varies within the interval $0-6^{\circ} \mathrm{C}$.
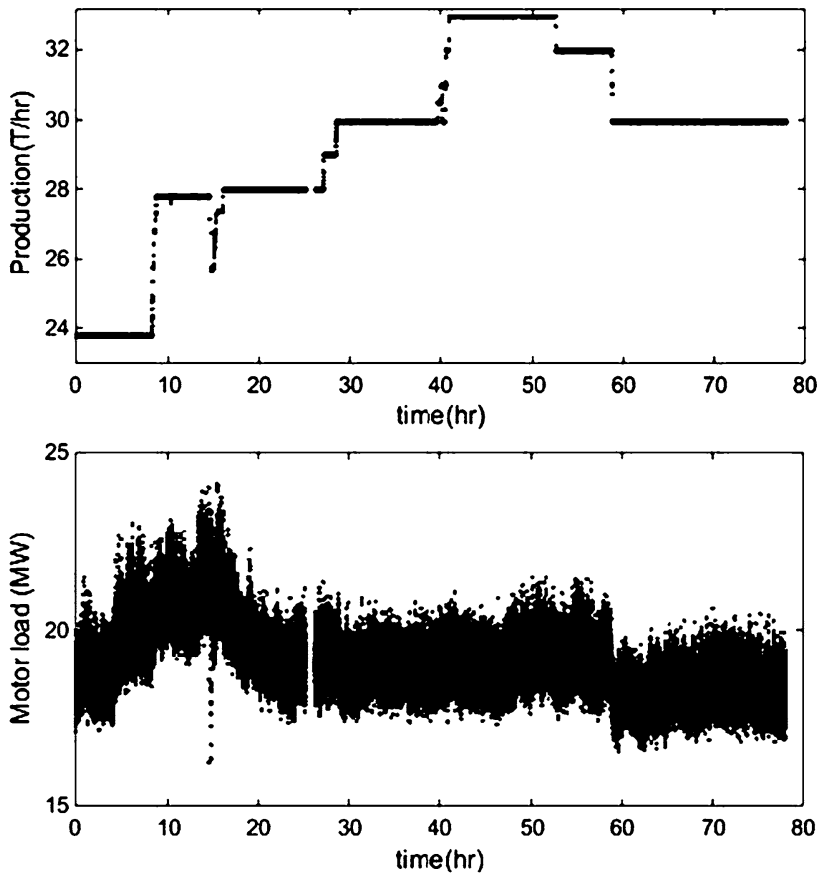

Figure 8: Production changes during the test and response in motor load including time for each test point.

pendix. The shape of the consistency profile is of course changed over time, which affect the fiber residence time and thereby the final pulp and handsheet properties, see Karlström and Hill (2017a,b,c). Therefore, the equal consistency in the refining zone outlets should be seen as a first starting point in the optimization procedure.

Note that a good choice is to find dilution water feed rates that correspond to about $45-50 \%$ in the consistencies out from the refining zones.

Later on we will discuss how to optimize the consistencies to approach desired pulp and handsheet properties.

Optimizing production: When maximizing the production in a CD refiner, it is necessary to manipulate the plate gap and dilution water to the $\mathrm{CD}$ zone without violating the pulp quality. In many situations, increased production means that the plate gap in the conical zone must be increased at the same time as the plate gap in the flat zone is reduced to provide reasonable refining conditions. ${ }^{9}$ This coincides with the ideas provided in Equation 5 as the maximum temperature in the flat zone will be increased while the maximum temperature in the conical zone will be slightly reduced. It is also important to

9 If this procedure is not performed, the conical zone will run into a situation where the process is not controllable as the volume in the conical zone is not large enough to handle the increased production which will ultimately result in a refiner cut down. 


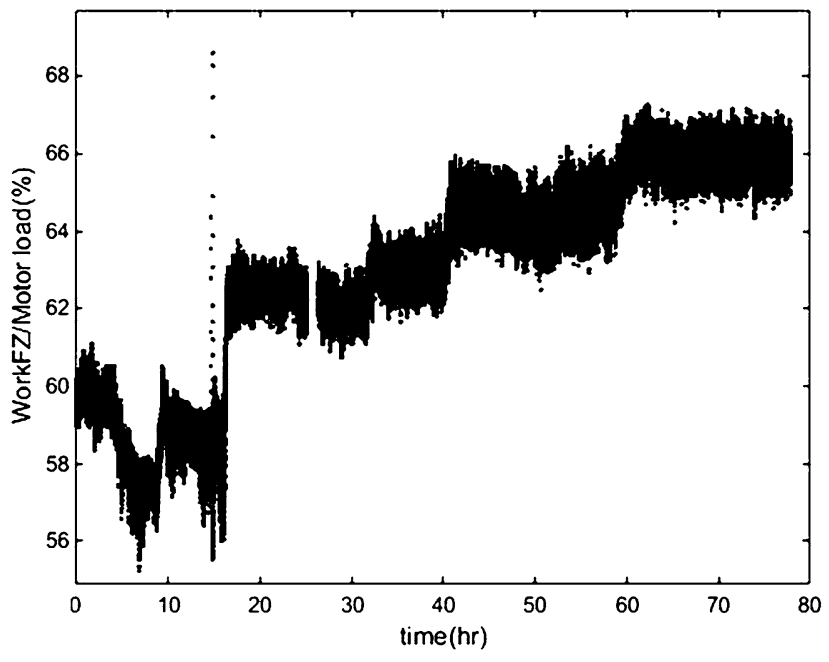

Figure 9: Ratio between the estimated work in the flat zone and the total motor load.

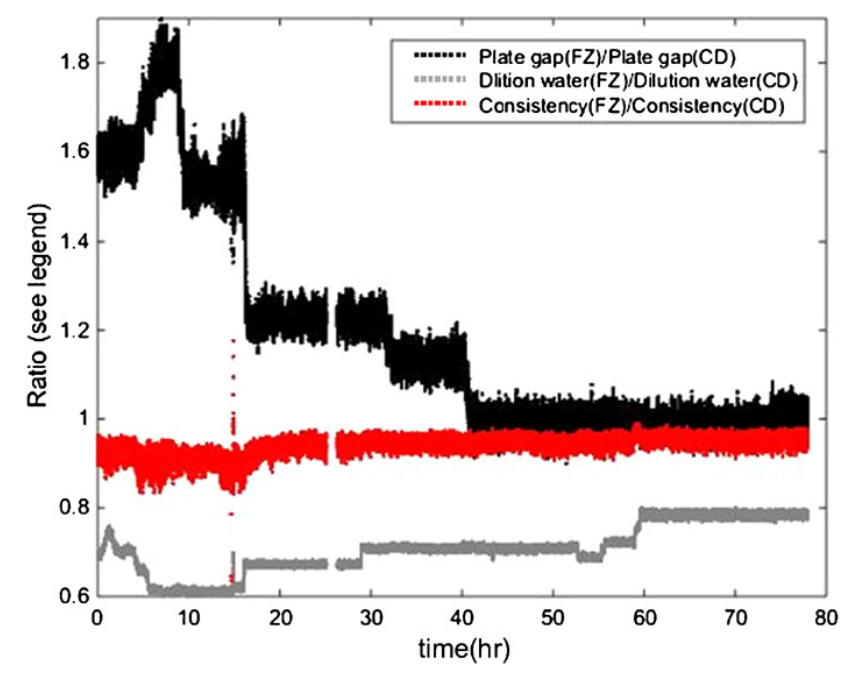

Figure 10: The ratios between selected external and internal variables in the flat zone and conical zone. The ratios highlight the strategy to keep a stable consistency ratio when running the test according to Figure 6.

maintain the condition in Equation 6 when changing the operating point as it is otherwise easy to get "wrong" consistency profiles inside the refining zones. Therefore, the consistency controllers in Figure 4 can also be maintained in automatic mode when changing production level.

It is important, when studying the test procedure in Figure 6, to understand that the manipulating strategy for the plate gaps and dilution water feed rates in FZ and CD resulted in a possibility to increase the production at the same time as the motor load was relatively stable during the optimization. This is a consequence of the changed motor load split between the flat zone and the conical

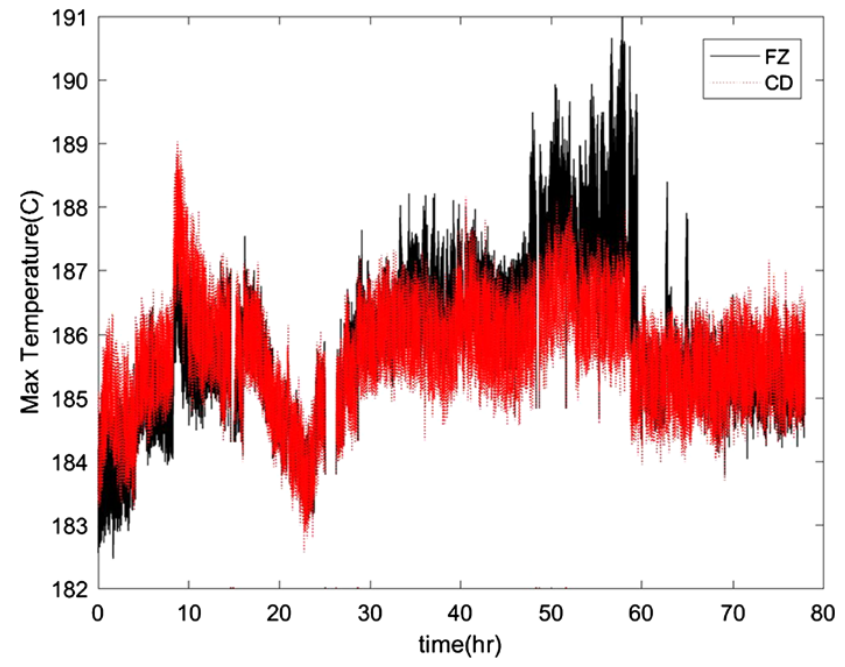

Figure 11: Temperature maximum in $F Z$ and $C D$, respectively. No maximum temperature control during the test.

zone, see Figure 9, when manipulating the plate gaps according to Figure 10.

During the process when changing the operating point it is clear that the consistency can be controlled while the maximum temperature cannot. This statement is strengthened by studying Figure 11, where the temperature responses vary considerably when the process conditions are changed according to Figure 6.

We can conclude that the major test started at $t=$ $9 \mathrm{hr}$. The consistencies in both refining zones were almost equal. The production was initially changed before modifying the relationship between the plate gaps in the refining zones, which started at $t=16 \mathrm{hr}$ and stabilized after $t=20 \mathrm{hr}$. Thus, the plan to manipulate the plate gaps before increasing the production was not followed, but this did fortunately not ruin the test; the accelerometers in the conical zone indicated a significant reduction, see Figure 12.

The accelerometers in both zones are identical, and it is interesting to see that the monitored vibration in the flat zone is only slightly affected by the extra load. This is likely a consequence of the fact that the capacity in terms of free volume is larger in the flat zone compared with the conical zone.

More can be said about this test procedure, especially when it comes to the statement in Equation 5. As can be seen in Figure 13, the desired relationship between the maximum temperatures in the refining zones is not followed completely. The reason was that the importance of getting a higher temperature maximum in FZ compared with CD was not originally known.

After a closer study of Figure 14, especially the period after $t=20 \mathrm{hr}$, it clear that the consequence of having too 

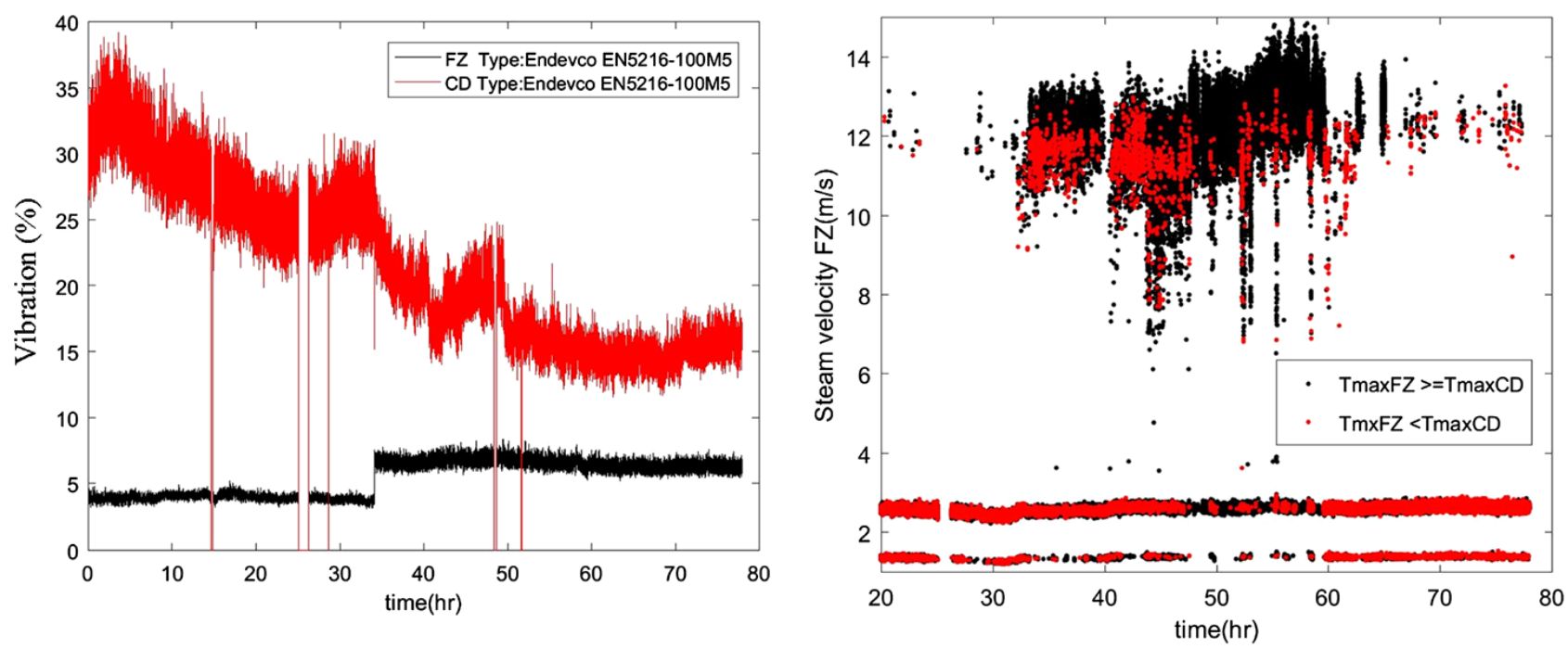

Figure 12: Acceleration in the refining zones during the test procedure outlined in Figure 6. Endevco; Accelerometer interval 0$10 \mathrm{~mm} / \mathrm{s}$.
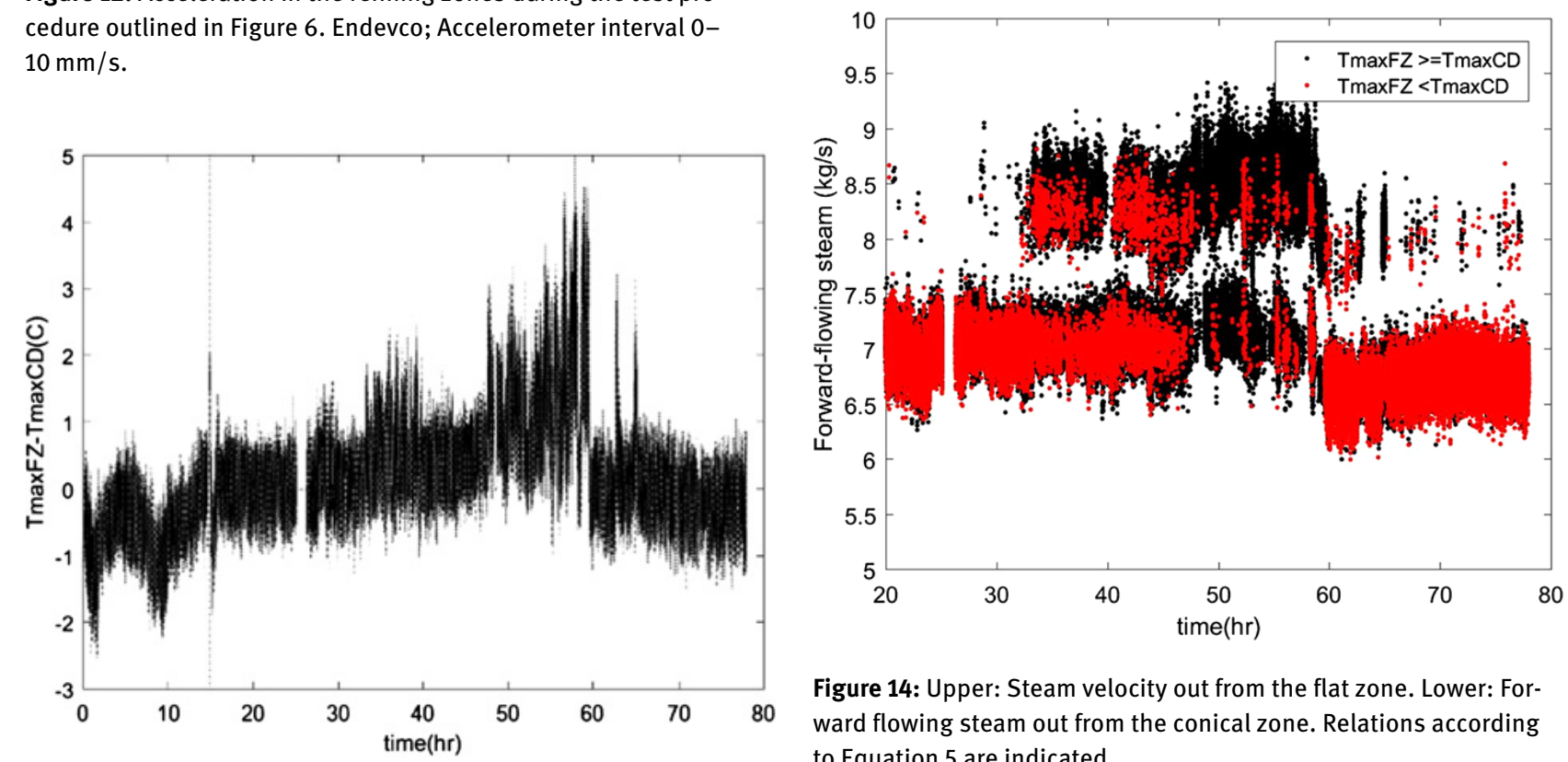

Figure 14: Upper: Steam velocity out from the flat zone. Lower: Forward flowing steam out from the conical zone. Relations according to Equation 5 are indicated.

Figure 13: Difference in maximum temperature in the flat zone and conical zone. Test procedure stabilized after $t=20 \mathrm{hr}$.

low a temperature maximum in the flat zone will cause considerable fluctuations in the steam velocity in the flat zone, which ultimately affects the amount of forward flowing steam out from the conical zone. Therefore, we can conclude that, if securing the relationship in Equation 5, the daily steam production to the reboiler would be possible to increase about $86 \mathrm{~T} /$ day (in this specific example).

What we can also extract from Figure 14 is that the maximum temperature in the flat zone is not optimized in space. This can be concluded from the upper figure, where three distinct levels for the steam velocity appear. For this specific set of refining segments the temperature becomes very flat, which makes the position for the max-

imum temperature switch about $100 \mathrm{~mm}$ back and forth, see Figure 15, resulting in an unnecessary pumping effect which is far from an optimized situation. Therefore, the next step should have been to reduce the plate gap in the flat zone even further.

It is worth mentioning that the forward flowing steam also can be controlled by designing the refining segments so that the contraction point for the taper comes at an earlier position. ${ }^{10}$

10 This is also indicated in Figure 21 in the Appendix where the left figure corresponds to a situation optimized to get maximized forward flowing steam while the right figure refers to a not optimized operating point. Instead, this figure can be seen as a typical process situ- 


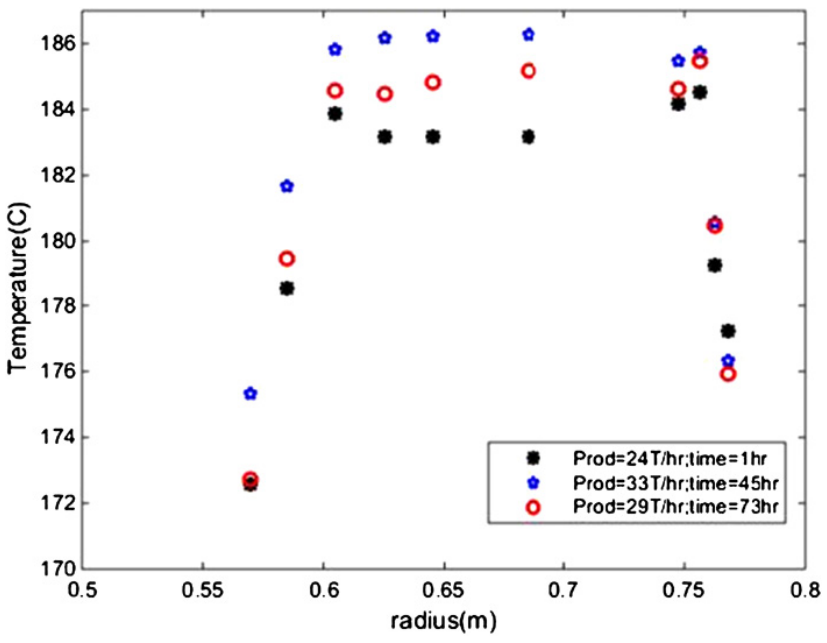

Figure 15: Temperature profiles at three production levels.

Tuning pulp and handsheet properties: When the desired operating point is reached, the next step is to set the maximum temperature controller in auto-matic mode and control the process given in Equation 3.

As can be seen in Equation 2, the pulp and handsheet properties can be controlled if the elements $\left\{g_{51}, \ldots, g_{55}\right\}$ are known. However, we have concluded from earlier experiments that these transfer functions are non-linear and difficult to derive in a proper way to get a good dynamic representation valid over time, see Karlström et al. (2015, 2016a,b). Therefore, the strategy is to use the models provided by Equation 4 and Table 1.

It is obvious that an increased production such as the one discussed above will affect the final product. This is easy to see by studying the changes in shives during the test procedure, see Figure 16 . Both the long and wide measures for shives increase slightly.

During the test, the estimates of consistency and fiber residence time vary according to Figure 17 . It is clear that the residence time correlates with plate gap and the production level. Furthermore, the residence time in the conical zone is much smaller than in the flat zone.

As can be seen in Figure 18, the major dynamics in the measured long shives are kept by introducing both consistencies and the residence time in the flat zone as predictors. Introducing the residence time in the conical zone improves the estimate to some extent and reduces the variance but does not affect the trend.

ation where the back-flowing steam is maximized, i.e. an operating point that is easy to encounter if one does not follow the guidelines given by Equation 5 and Equation 6 .
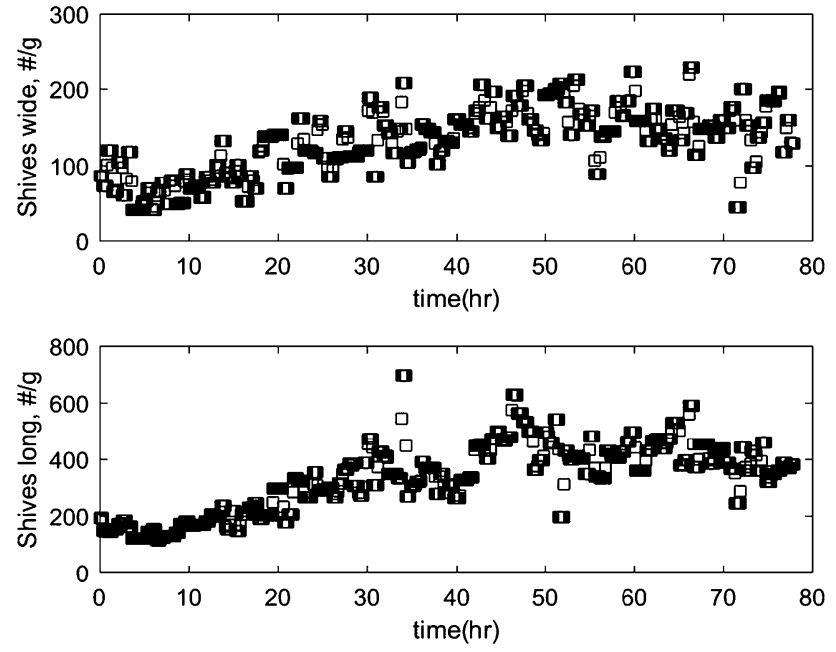

Figure 16: Measured wide and long shives versus time during the test procedure.

It is worth mentioning that, during the test, no fine tuning of the pulp and handsheet properties was performed. However, now when we have all results, it is easy to explain what we should have done - suppose that we want to reduce the long shives content by manipulating the consistency $C_{\max Z}$ and $C_{\max C D}$ according to the linear model in Equation 4 with the parameter vector $\theta=$ $\left\{b, C_{\max F Z}, C_{\max C D}, r_{F Z}, r_{C D}\right\}=\{287,37,-28,-2333,12640\}$, where $b$ corresponds to the intercept and $r_{F Z}$ and $r_{C D}$ to the residence times.

The parameters indicate that the consistencies in each refining zone affect the long shives in the opposite direction. A reduction of $5 \%$ in the flat zone will reduce the long shives by approximately $50 \# / g$ as the consistency in the conical zone is affected as well.

It is also possible to independently increase the consistency in the conical zone by $5 \%$ and thereby reduce the long shives about $100 \# / g$ further.

Note that the equality in Equation 6 should not be used in this optimzation procedure and the consistencies in the refining zones are controlled independently from each other.

When it comes to the residence time, it is hard to reduce this further in the conical zone. This means that the only practical manipulation left is to increase the residence time in the flat zone by further reducing the plate gap. This is most likely possible, which means a reduction in long shives by about at least $50 \# / \mathrm{g}$.

In total, it would be possible to reduce the long shives at least $200 \# / g$ by manipulating the consistencies and the fiber residence time in the flat zone in a proper and con- 

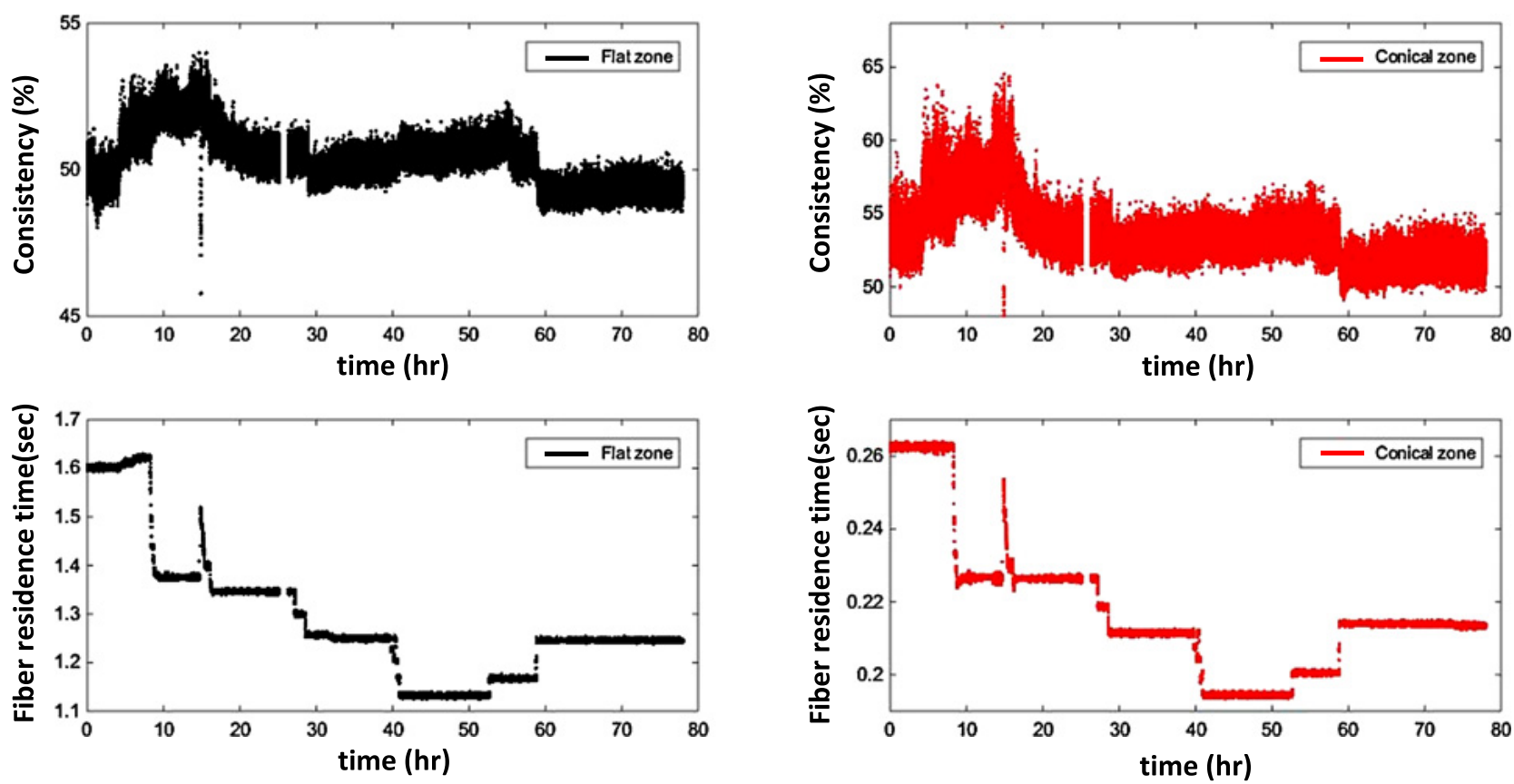

Figure 17: Upper left and right: Responses in the consistencies out from FZ and CD. Lower left and right: Residence times in FZ and CD.

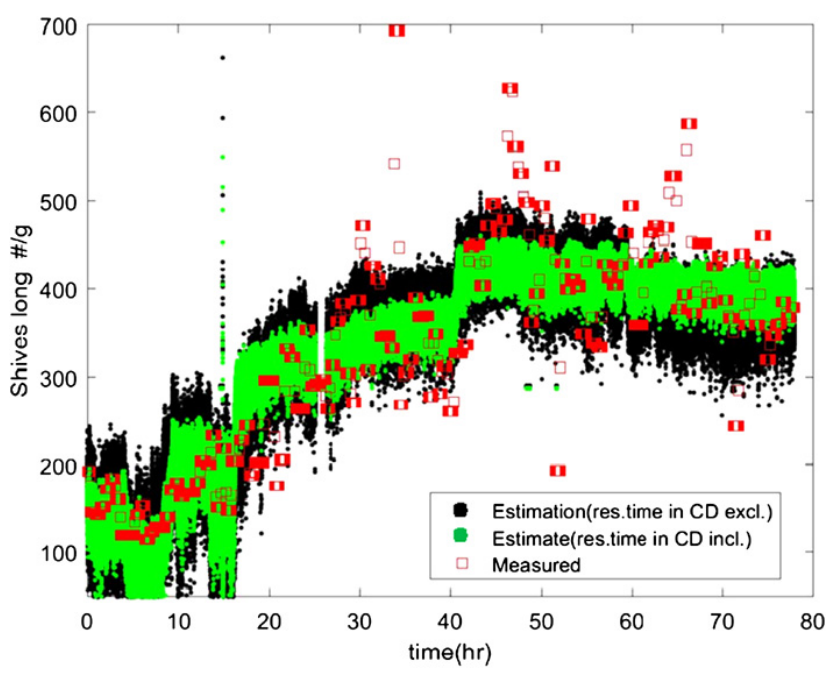

Figure 18: Measured shives long $(\# / g)$ and corresponding estimates using the parameter vector $\theta=\left\{b, C_{F Z}, C_{C D}, r_{F Z},\right\}$ and $\theta=\left\{b, C_{F Z}, C_{C D}, r_{F Z}, r_{C D}\right\}$, respectively.

trolled way. Thereby, we are back to the original quality when the test was started.

Often the long shives are not in focus in the final control strategies as the increase in Figure 18 is normally within the property specification. However, it gives an indication of how the tensile index and Scott bond varies as well.

If it is attempted to control for instance the Scott bond instead, using $\theta=\left\{b, C_{\max Z}, C_{\max C D}, r_{F Z}, r_{C D}\right\}=$
$\{160,-7.2,3.6,120.8,-508.4\}$, it is possible to follow the same logics. All documentation can be found in articles by Karlström and Hill (2017a,b,c). In this case it is clearly in favor to reduce the consistency in the flat zone and increase it in the conical zone, similar to the situation when optimizing the long shives. According to the model, it should be possible to gain about $25-30 \mathrm{~J} / \mathrm{m}^{2}$ only by manipulating the consistencies. In this case it is questionable whether the Scott bond can be changed further by manipulating the fiber residence time in the flat zone. $10-15 \mathrm{~J} / \mathrm{m}^{2}$ is questionable for a change in plate gap. To illustrate the technics how to use the predicted properties in future pulp and handsheet property estimators, Scott bond, tensile index, mean fiber length (MFL) and Canadian Freeness are included in Figure 19.

The sheet density model used the parameter vector $\theta=$ $\left\{b, C_{\max Z}, C_{\max C D}, r_{F Z}, r_{C D}\right\}=\{376.4,-13.6,7.6,100.9,55.8\}$ and was verified by manual testing according to Figure 20 . Increasing the sheet density by changing the consistency follows the same pattern as the Scott bond and the tensile index models, while it is slightly different when changing the residence time in the conical zone. However, the magnitude in the parameter $r_{C D}$ is much smaller than the same in the Scott bond model.

Note that the models, described in Table 1, are based on background data used in Karlström and Hill (2017a,b,c). These models are thereafter applied to data 

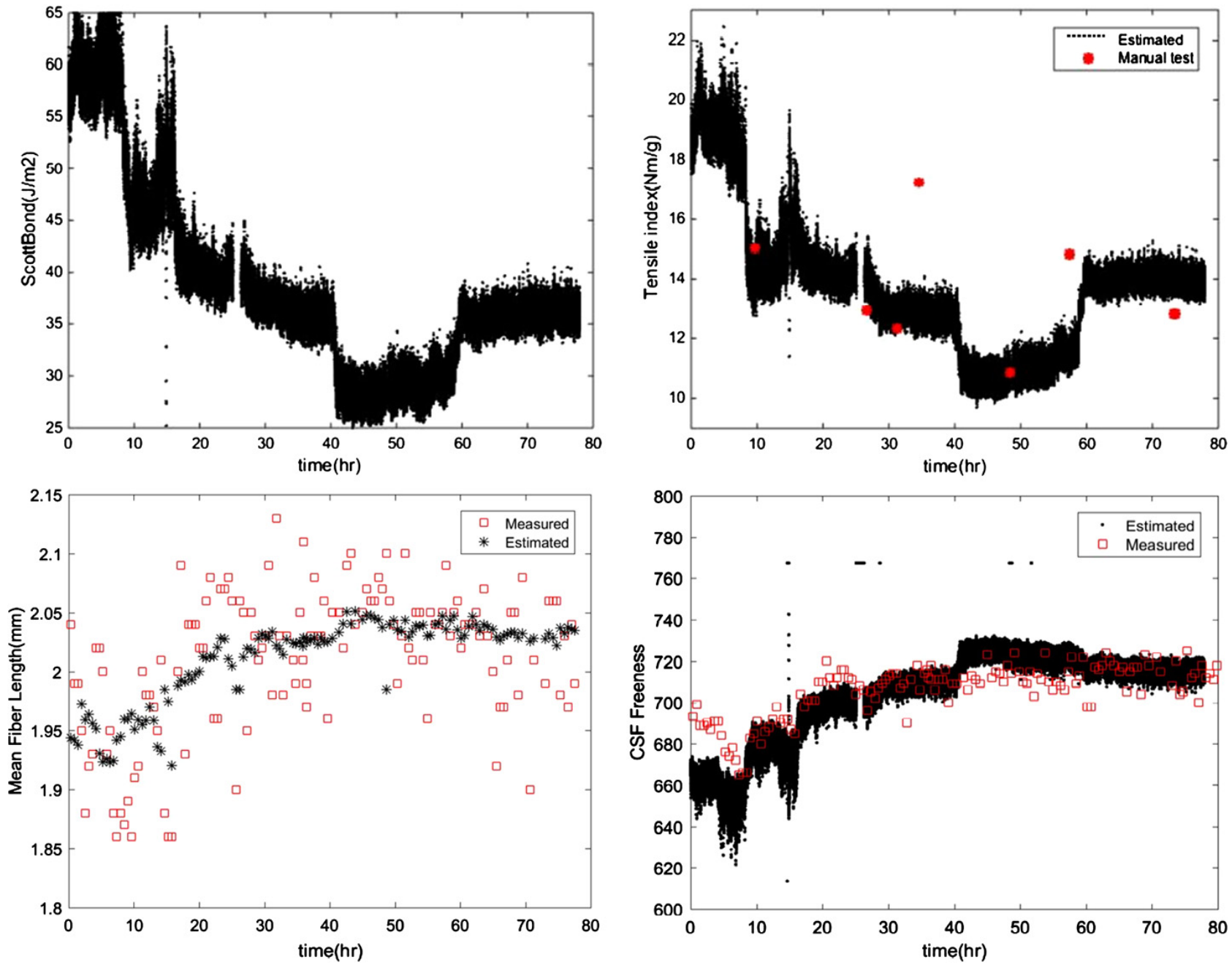

Figure 19: Upper left: Estimated Scott bond. Upper right: Estimated and measured tensile index. Lower left: Measured and estimated mean fiber length. Lower right: Measured and estimated CSF.

from the test outlined in this paper. We therefore expected that the models should not be valid, as a completely new set of refining segments with a new pattern was used in this test. Nevertheless, it was interesting to see that the intercepts (b) were the only parameters in the model we needed to change slightly. The intercepts in the original model for Scott bond and Sheet density were 155, 311 while intercepts in the modified model were higher, see above. This means that the elements of the parameter vector seem to be useful even though new segments are used. Moreover, in control applications, it is more important to know the direction of a change in the predictors as compared with the absolute value. This opens for on-line applications where laboratory data tests can be used for future machine learning algorithms.

As a final remark: In Figure 17, it is interesting to see that we have potential outliers in the measurements. These are probably a consequence of the inherent measurement statistics and mixing effects in the latency chest. Estimating the long shives using the procedure given above can to some extent be favorable in optimizing the process.

In summary, when the optimization is performed in this paper, we can conclude that the consistency in the flat zone should be slightly lower than the outlet consistency in the conical zone if the strategy is to maintain the pulp and handsheet properties at the same level as before the increase in production, i.e.

$$
C_{\max F Z}<C_{\max C D}
$$

However, if the pulp and handsheet properties are within the pre-specified interval, it is natural to select an operating point at which the refiner is running as smoothly as possible. 


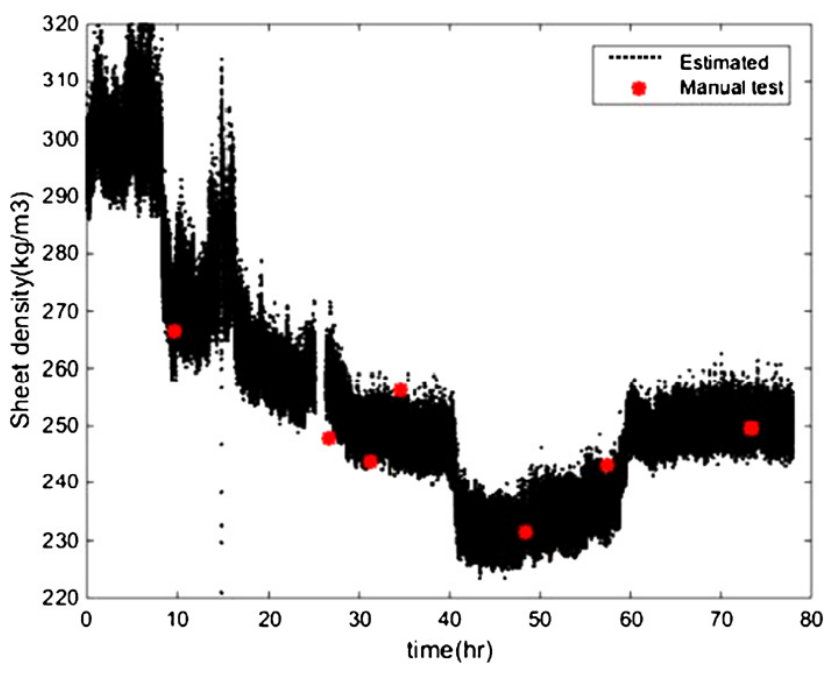

Figure 20: Measured and estimated sheet density using the parameter vector $\theta=\left\{b, C_{F Z}, C_{C D}, r_{F Z}, r_{C D}\right\}$.

\section{Concluding remarks}

The main purpose of this paper is to show how to use the internal variables (specifically, temperature profile, consistencies and fiber residence times together with backward- and forward-flowing steam) in a new concept for $\mathrm{CD}$ refiner control. It is claimed that the internal variables can be a backbone in future control concepts of CD refiners. This is strengthened by analyzing the control efforts from three different perspectives to 1) reach desired operating conditions by manipulating the maximum temperatures and outlet consistencies out from the flat and conical zones followed by 2) optimize the production (if requested) and finally 3) implement the complete set of control algorithms in automatic mode to maintain the process at the desired production level to stabilize the pulp and handsheet properties in time.

It is shown how important the shape of the temperature profile is when optimizing the forward-flowing steam. It is concluded that, if the maximum temperature in the flat zone is located closer to the center, more forward-flowing steam is obtained.

The marginal production of steam to the reboiler is sometimes overlooked, but optimizing the steam balance can easily improve the steam balance by $80-90 \mathrm{~T} /$ day.

It is moreover shown that the maximum temperature in FZ must be stable and higher than the maximum temperature in the conical zone to reduce pumping effects in the fiber pad, which can severely affect the fiber development. This is not very often addressed but will help operators to stabilize both the backward- and forward-flowing steam.
During the test, the motor load split was changed from the traditional way of loading the conical zone to a more unorthodox strategy where the flat zone was controlled to open for an increase in production. This was possible thanks to the consistency estimation in both zones. The periphery consistencies were initially set equal to reach the desired production level and thereafter changed to optimize the pulp and handsheet properties within a prespecified interval.

Even though the production was increased, the monitored vibration in the conical zone was reduced significantly due to the new way of refiner operation. This is indeed a good sign, especially as it indicates that the fiber development most likely is more homogeneous in the conical zone due to fewer process variations.

In summary, we can conclude that it is possible to optimize the process to reduce the specific energy significantly without violating the pulp property specification.

Acknowledgments: Special thanks go to the StoraEnso Skoghall mill, for running trials and providing the excellent laboratory and process data used in this study.

Funding: The authors gratefully acknowledge the funding by the Swedish Energy Agency, StoraEnso and Holmen Paper.

Conflict of interest statement: The authors do not have any conflicts of interest to declare.

\section{Appendix}

The flow pattern in the refining zone is set by three physical states (chips/fibers, water and vapor) that must be considered simultaneously. The steam generated in the refining zone is commonly assumed to be saturated, i. e. the pressure is a function of the temperature and vice versa, regardless of which type of high-consistency refiner is studied.

There is no doubt that the temperature measurements can be seen as internal variables measured inside the refining zone, and it is easy to understand that using a model that describes the major physical phenomena in a refining zone provides a possibility to predict several other internal variables such as:

- Forces on bars (Karlström and Eriksson (2014a,b));

- Consistency profile (Karlström and Hill (2017a,b,c)); 

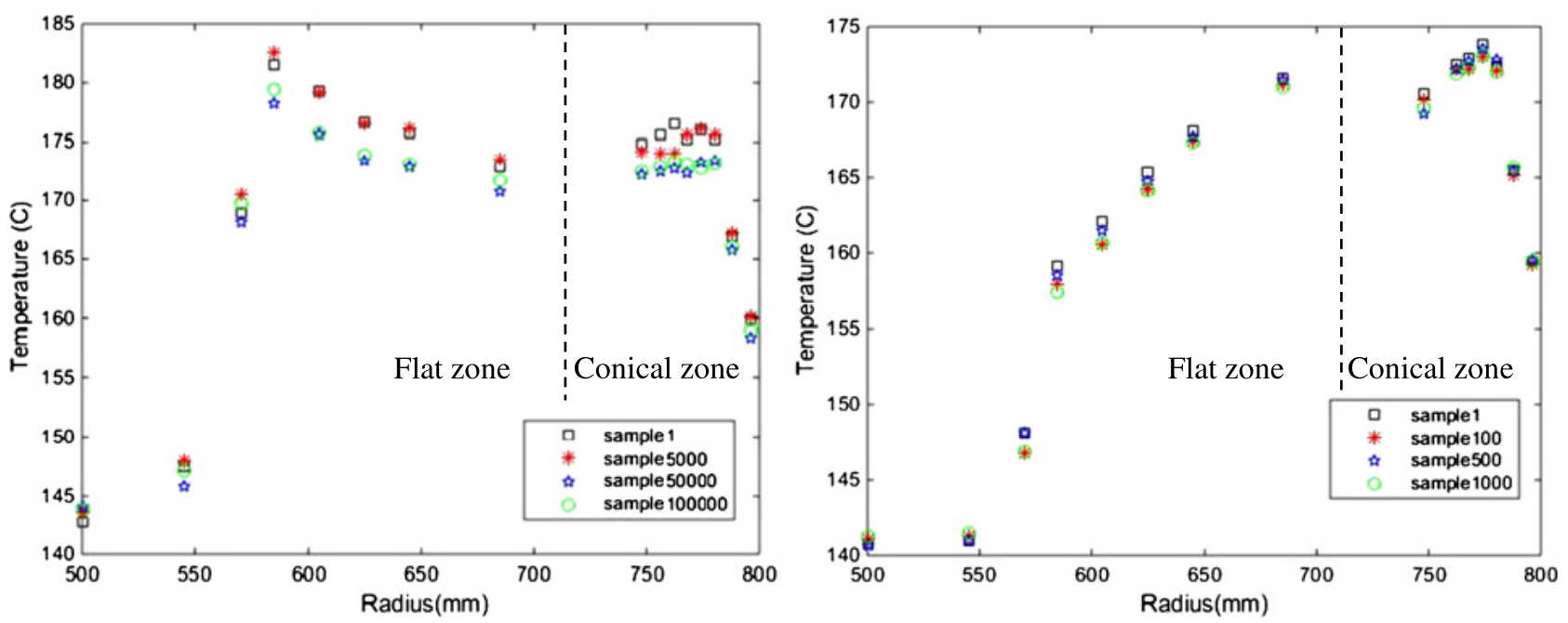

Figure 21: Temperature profiles at two different test trials and the same type of refining segments. Plots spread over 1000 samples (seconds) in a CD82 refiner. The radius is calculated using information about $\beta$ in Figure 2.

- Fiber residence time possible to define spatially dependent on segment pattern etc. (Karlström and Hill $(2017 \mathrm{a}, \mathrm{b}, \mathrm{c}))$;

- Defibration work and thermodynamic work important for the entire steam balance (Karlström et al. (2008));

- Back-flowing steam used to predict incoming chip moisture (Karlström and Hill (2017a));

- Pulp, water velocity and steam velocity vital when analyzing e.g. feeding problems at different production levels (Karlström et al. (2016a)).

Such measurements or estimates together with traditional process variables, such as dilution water flows, plate gaps and specific energy, are vital in terms of spanning the material and energy balances. The traditional process variables are consequently called external variables as they are measured outside the refiner or, like the plate gaps, can be classified as not typical physical phenomena. ${ }^{11}$

From a modeling perspective, it is important that the physical properties are available at different radial positions and scales, as these variables are dependent on e.g. type of refining segments and actual process conditions.

It is also important that the model can handle the energy input (motor load) as a distributed work in the refining zone from a macro-scale perspective, see Figure 2 in the main text. Karlström and Eriksson (2014a,b,c,d) focused on describing the model with a distributed viscosity model, and this expansion formed the "extended entropy

11 In this context, the specific energy is also classified as an external variable even though the motor load, which is the integral of all work distribution in the refining zone, can be seen as an internal variable. model," which was a set of material and energy balances for one refining zone.

The reason why the model refers to the entropy instead of the enthalpy is that the entropy generation

$$
d S(r)=\frac{d E(r)}{T(r)}
$$

is introduced as an important variable to distinguish between thermodynamic work given by the change in enthalpy and defibration/fibrillation work. Thus, $d E$ refers to the energy dissipated and $T$ is the absolute temperature.

In former model assumptions (Miles and May, 1990), a pure enthalpy balance was considered, $d H=d E$, where $d H$ is the enthalpy generation, which did not consider the irreversible work related to the fiber development, i. e. the entropy generation, and $d S$ in an infinitesimal control volume is assumed to be given by the expression for the viscous dissipation, $\delta$ (Bird et al. 1960).

$$
d S(r)=\frac{\delta(r)}{T(r)} \Delta(r) 2 \pi r d r
$$

where

$$
\delta(r)=\mu\left(\frac{r \omega}{\Delta(r)}\right)^{2}=\frac{w_{R}(r)}{\Delta(r)}
$$

Karlström and Eriksson (2014a,b,c,d) showed that it is important to measure both the temperature profile $T(r)$ and get a dynamic indication of how the plate gap profiles $\Delta(r)$ in the refining zone vary, ${ }^{12}$ together with the entire motor load, $w_{R}$, when deriving the dynamic viscosity $\mu(r)$.

12 The absolute measurements of the plate gap are challenging even though an AGS sensor is used, see Karlström and Hill (2017a,b,c). However, a relative measurement is also valuable for modeling purposes. 


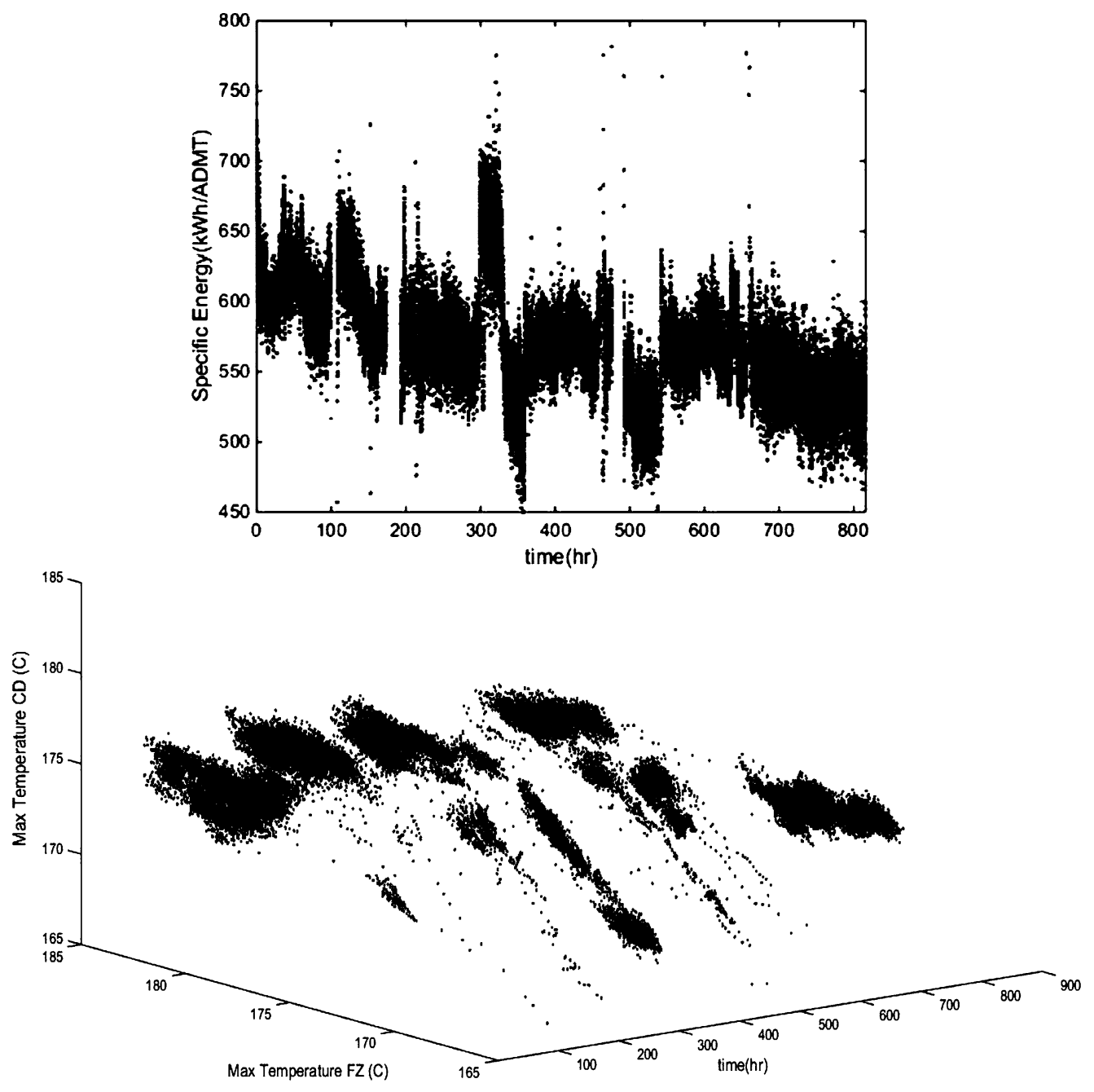

Figure 22: Upper figure: Specific energy vs. time. Lower figure: Temperature in FZ and CD vs. time.

Measuring the temperature profile is important for many reasons as it gives information about where to find the position of the temperature maximum.

As the steam evacuates both forward (towards the periphery of the segments) and backward (towards the inlet), the position can be seen as a stagnation point, which implies a zero pressure gradient, $\partial P / \partial r$, see Figure 21, where two temperature profiles are shown for a CD82 refiner.

The stagnation points depend on the type of refining segments used and can be seen as a cornerstone when describing the steam balance in the refiner.

Although the stagnation points in $\mathrm{CD}$ refiners are sometimes overlooked, it turns out that they are vital when deriving both backward and forward flowing steam. ${ }^{13}$

13 The steam balance is not in focus in this paper, but it is interesting that so little attention has been given to this topic in the literature as
It is especially important to stabilize the position of the maximum temperature when running low energy segments to avoid large steam fluctuations in the refining zone and the feeding position in the inlet, which ultimately affect the pulp and handsheet properties. This might be considered obvious, but temperature profiles are often not available for more advanced refiner control, which makes it difficult to foresee fiber pad fluctuations by only studying the specific energy variations, see Figure 22. When modeling refining zone conditions, the position of the stagnation point also becomes important as the steam balance affects a number of internal variables, e. g. the consistency profile and the variance in consistency in different positions. Earlier, the consistency profile in the flat zone was not avail-

it directly relates to the steam economy in the mill. This was partly described in Karlström and Hill (2014a), where the concept of steam efficiency was discussed. 


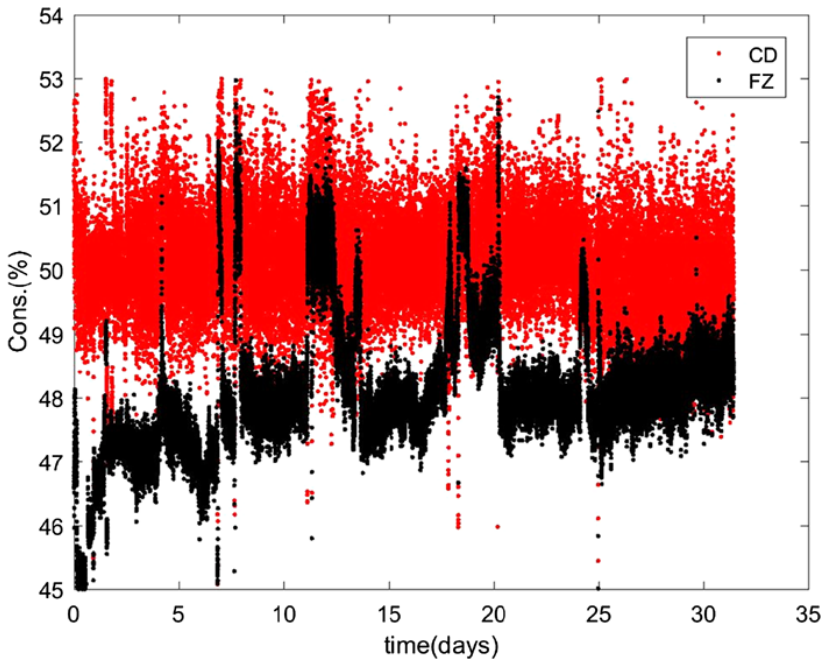

Figure 23: Consistencies in the conical and flat zones.

able. This was a consequence of the fact that only external variables were used when estimating the blow-line consistency. Karlström et al. (2015, 2016a,b) showed that the flat zone consistency also plays a vital role when trying to optimize the pulp and handsheet properties. They showed that estimated consistencies out from the flat and conical zones provide a possibility to find more stable operating points. As an example, in Figure 23, the flat zone consistency varies considerably and the high frequency variance is relatively low compared with the variance in the conical zone. To reduce the variance in the CD zone, it is important to find another operating point by introducing a more advanced control concept compared with present manual control.

The extended entropy model, illustrated in Figure 24 for a $\mathrm{CD}$ refiner, is somewhat complex, and the reader is referred to Karlström and Eriksson (2014a,b,c,d) for details.

In Figure 24, the inlet mixing point is the position where wood chips meet dilution water added to the inlet zone while the inlet mixing zone corresponds to the zone close to the flat zone, where the inlet pressure of possibly added steam meets the chips and water. The flat zone (FZ) energy and material balances $1, \ldots, n_{1}$ comprises $n_{1}$ sensors, where detailed information about the process can be derived. The mixing point between flat zone and CD zone illustrates the position at which the dilution water is added to the $\mathrm{CD}$ zone. This is a central variable as it is vital for the distributed work and for the consistency estimations. The CD zone energy and material balances $1, \ldots, n_{2}$ comprise $n_{2}$ sensors and are in many aspects similar to the corresponding FZ block. The outlet mixing zone describes the mass flows out of the $\mathrm{CD}$ zone. Most often this zone is as-

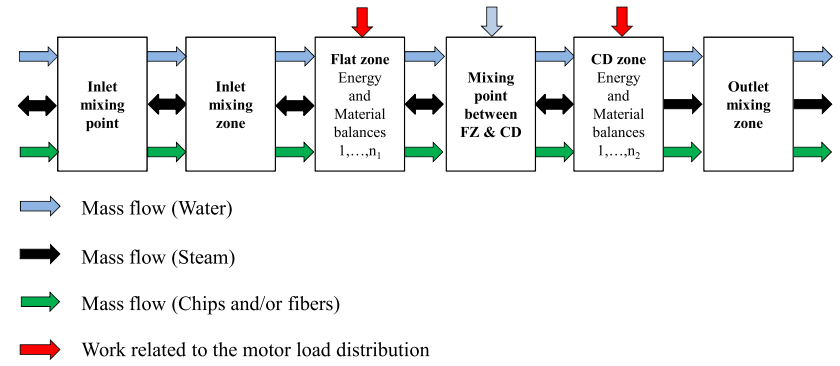

Figure 24: Schematic description of the material and energy balances spanning the $\mathrm{CD}$ refiner.

sociated with a flash calculation, as the temperature and pressure are normally lower in this position as compared with inside the $\mathrm{CD}$ zone. The model described schematically in Figure 24 is a physical non-linear model which is designed for on-line applications at sampling rates down to one second.

It is well known that refiner control strategies differ from one mill to another. In CD refiners, the concept has been focused on how the conditions in the conical zone are controlled. However, Karlström and Hill (2017a,b,c) showed that new control concepts can be introduced if the flat zone is also considered when trying to reduce different disturbances and interactions. This paper is an attempt to summarize the findings on how to use internal variables such as temperature profile, consistency and fiber residence time.

\section{References}

Berg, D. (2005): A Comprehensive Approach to Modeling and Control of Thermomechanical Pulping Processes, Lic thesis. Dept. of Signals and Systems, Chalmers.

Bird, R. B., Stewart, W. R. and Lightfoot, E. N. (1960): Transport phenomena, John Wiley and Sons Inc., New York.

Dahlqvist G. and Ferrari B. (1981): Mill operating experience with a TMP refiner control system based on a true disc clearance measurement, In: Int. Mech. Pulping Conf., Oslo, Norway, Session III, no. 6.

Eriksson, K. (2005): An Entropy-based Modeling Approach to Internally Interconnected TMP Refining Processes, Licentiate thesis, Chalmers University of Technology, Göteborg, Sweden. ISSN 1403-266x; nr R034/2005.

Eriksson, K. (2009): Towards improved control of TMP refining processes, PhD thesis, Chalmers University of Technology, Göteborg, Sweden.

Hägglund, T., (1999): Automatic detection of sluggish control loops, Control Eng. Pract. 13:1383-1390.

Hill, J., Saarinen, K., Stenros, R. (1993): On the control of chip refining systems, Pulp Pap. Can. 94(6):43-47. 
Hill, J., Westin, H., and Bergström, R. (1979): Monitoring pulp quality for process control, In: Int. Mech. Pulping Conf., Toronto, Canada, p. 111-125.

Honkasalo, J. V., Pölkkynen, E. E., Vainio,J. A., (1989): Development of control systems in mechanical pulping (GW, TMP) at Rauma, In: Int. Mech. Pulping Conf., Helsinki, Finland, p. 376-389.

Horch, A., (1999): A simple method for detection of stiction in process control loops, Control Eng. Pract. 7(10):1221-1231.

Isaksson, A. J., Horch, A., Karlström, A., Allison, B. J., Nilsson, L. (1997): Modelling of mechanical thrust in TMP refiners, Prceedings, In: Int. Mech. Pulping Conf, SPCI, Stckhm., p. 87-93.

Johansson B.-L., Karlsson H. and Jung, E., (1980): Experiences with computer control, based on optical sensors for pulp quality, of a two-stage TMP-plant, In: 1980 Process Control Conf., Halifax, Nova Scotia, p. 145-152.

Karlström, A., (2013): Multi-scale modeling in TMP-processes, In: $8^{\text {th }}$ Int. Fundamental Mech. Pulp Res. Seminar, Åre, Mid Sweden Univrersity, Sundsvall, Sweden.

Karlström, A., Berg, D. and Eriksson, K. (2005): Developments in soft sensors for measurement of refining parameters, In: Scientific and technical advances in refining and mechanical pulping, Barcelona, Spain, 28 Feb.-4 Mar. 2005, Pira International, Leatherhead, UK, Paper 5.

Karlström, A. and Eriksson, K. (2014a): Fiber energy efficiency Part I: Extended entropy model. Nord. Pulp Pap. Res. J. 29(2):322-329.

Karlström, A. and Eriksson, K. (2014b): Fiber energy efficiency Part II: Forces acting on the refiner bars. Nord. Pulp Pap. Res. J. 29(2):332-343.

Karlström, A. and Eriksson, K. (2014c): Fiber energy efficiency Part III: Modeling of fiber-to-bar interaction. Nord. Pulp Pap. Res. J. 29(3):401-408.

Karlström, A. and Eriksson, K. (2014d): Fiber energy efficiency Part IV: Multi-scale modeling of refining processes. Nord. Pulp Pap. Res. J. 29(3):409-417.

Karlström, A., Eriksson, K. and Hill J. (2015b): Refiner Optimization and Control Part IV: Long term follow up of control performance in TMP processes. Nord. Pulp Pap. Res. J. 30(3):426-435.

Karlström, A., Eriksson, K., Sikter, D. and Gustavsson, M. (2008): Refining models for control purposes, Nord. Pulp Pap. Res. J. 23(1):129.

Karlström, A. and Hill J. (2014a): Refiner Optimization and Control Part I: Fiber residence time and major dynamic fluctuations in TMP refining processes. Nord. Pulp Pap. Res. J. 29(4):635-652.

Karlström, A. and Hill J. (2014b): Refiner Optimization and Control Part II: Test procedures for describing dynamics in TMP refining processes. Nord. Pulp Pap. Res. J. 29(4):653-662.

Karlström, A. and Hill J. (2015a): Refiner Optimization and Control Part III: Natural decoupling in TMP refining processes. Nord. Pulp Pap. Res. J. 30(3):417-425.
Karlström A., Hill J. (2017a): CTMP process optimization Part I: Internal and external variables impact on refiner conditions. Nord. Pulp Pap. Res. J.. 32(1):35-44.

Karlström A., Hill J. (2017b): CTMP Process Optimization Part II: Reliability in Pulp and Handsheet Measurements. Nord. Pulp Pap. Res. J. 32(2):253-264.

Karlström A., Hill J. (2017c): CTMP Process Optimization Part III: On the Predicition of Scott-Bond, Z-strength and Tensile index, Nord. Pulp Pap. Res. J. 32(2:266-279).

Karlström, A., Hill J., Ferritsius, R. and Ferritsius, O. (2015): Pulp Property Development Part I: Interlacing Undersampled Pulp Properties and TMP Process Data using Piece-wise Linear Functions. Nord. Pulp Pap. Res. J. 30(4):599-608.

Karlström, A., Hill J., Ferritsius, R. and Ferritsius, O. (2016a): Pulp Property Development Part II: Process Nonlinearities and its Influence on Pulp Property Development. Nord. Pulp Pap. Res. J. 31(2):287-299.

Karlström, A., Hill J., Ferritsius, R. and Ferritsius, O. (2016b): Pulp Property Development Part III: Fiber Residence Time and Consistency Profile Impact on Specific Energy and Pulp Properties. Nord. Pulp Pap. Res. J. 31(2):300-307.

Karlström, A., and Isaksson, A. (2009): Multi-rate optimal control of TMP refining processes, In: Int. Mech. Pulping Conf., Sundsvall, Sweden.

Lehtonen S., Virtanen P., Lindeberg M. and Fralic G. A. (2014): New TMP optimization approach: using advanced quality control to stabilize tensile strength and reduce power cost. In: International Mechanical Pulping Conference, Helsinki, Finland.

Lowe, G. K., Zohdy, M. A. (2010): Modeling nonlinear systems using multiple piecewise linear equations, Nonlinear Anal., Model. Control 15(4):451-458.

Miles, K. B. and May, W. D. (1990): The Flow of Pulp in Chip Refiners, J. Pulp Pap. Sci. 16(2):63.

Miles, K. B. and May, W. D. (1991): Predicting the performance of a chip refiner: A constitutive approach, Proceedings, In: Int. Mech. Pulping Conf. Tappi, Atlanta, pp. 295-301.

Oksum J., (1983): New technology in the Skogn mechanical pulp mill, Proceedings, In: Int. Mech. Pulping Conf., Tappi, Atlanta, USA, pp. 143-153.

Sabourin, M., Wiseman, N. and Vaughn, J. (2001): Refining theory considerations for assessing pulp properties in the commercial manufacture of TMP. In: $55^{\text {th }}$ Appita Annual Conference, Appita, Macled, Vic, Austraia, pp. 95-204.

Strand, B. C. (1996): Model based control of high consistency refining, Tappi J. 79(10):140-146.

Strand, B. C and Grace, B. (2014): Implementation of advanced supervisory control within a TMP refiner quality control system, In: International Mechanical Pulping Conference, Helsinki, Finland. 